Tema: Metalurgia Secundária

\title{
MODELAMENTO DA FORMAÇÃO DO “OLHO” E COMPORTAMENTO DE MISTURAMENTO EM PANELAS DE ACIARIA*
}

\author{
Augusto Pereira de Sá ${ }^{1}$ \\ Alexandre Leopoldo Pereira ${ }^{2}$ \\ Gabriel Romeu Trindade dos Santos ${ }^{2}$ \\ Carlos Antônio da Silva ${ }^{3}$ \\ Itavahn Alves da Silva ${ }^{4}$ \\ Eliana Ferreira Rodrigues ${ }^{5}$ \\ Varadarajan Seshadri ${ }^{6}$
}

\begin{abstract}
Resumo
Modelagens física e matemática foram utilizadas para avaliar os efeitos da geometria e parâmetros operacionais, tais como a vazão e distribuição de gás de agitação, além do nível de aço líquido no processo de mistura e formação de olho em panelas de aciaria. A influência de propriedades físicas, viscosidade e densidade, de escória e metal foi avaliada em um modelo físico, também empregado para medir a distribuição espacial das velocidades através de técnica PIV. São apresentadas correlações para o cálculo da abertura do olho e o efeito de frenagem da escória de topo é demonstrado.
\end{abstract}

Palavras-chave: Aciaria; Panela; Refino; Borbulhamento de argônio.

\section{MODELING EYE FORMATION AND MIXING BEHAVIOUR IN STEELMAKING} LADLES

\section{Abstract}

Physical and mathematical modeling have been used in order to assess the effects of geometry and operational parameters such as gas flow rate and gas distribution in addition to liquid steel level on mixing and eye formation inside steelmaking ladles. The influence of slag and metal viscosity and density have been assessed in a physical model which has been employed also for measuring spatial distribution of velocities through PIV technique. Correlation for estimating eye opening is presented and the retarding effect of top slag on mixing is demonstrated.

Keywords: Steelmaking; Ladle; Refining; Argon blowing.

1 Engenheiro Metalurgista, Mestrando em Engenharia de Materiais - REDEMAT, Universidade Federal de Ouro Preto (UFOP), Ouro Preto, MG, Brasil; augustopsa@yahoo.com.br.

2 Graduando em Metalurgia, UFOP, Campus Morro do Cruzeiro, Escola de Minas, Ouro Preto, MG, Brasil.

3 Engenheiro Metalurgista, Ph.D., Professor, Universidade Federal de Ouro Preto (UFOP), Campus Morro do Cruzeiro, Escola de Minas, Ouro Preto, MG, Brasil.

4 Engenheiro Metalurgista, DSc. Professor, Universidade Federal de Ouro Preto (UFOP), Campus Morro do Cruzeiro, Escola de Minas, Ouro Preto, MG, Brasil.

5 Engenheira Mecânica, DSc. Professora, Universidade Federal de Ouro Preto (UFOP), Campus Morro do Cruzeiro, Escola de Minas, Ouro Preto, MG, Brasil.

6 Engenheiro Metalúrgico, Dr. Ing. Professor Emérito, Universidade Federal de Minas Gerais (UFMG), Belo Horizonte, MG, Brasil.

\footnotetext{
* Contribuição técnica ao 450 Seminário de Aciaria - Internacional, 25 a 28 de maio de 2014,
} 


\section{INTRODUÇÃO}

A prática de borbulhamento de gás inerte, em panela de refino secundário do aço, tem como objetivo a uniformização térmica e composicional; aceleração das reações químicas, principalmente na interface metal-escória e na interface metal-bolhas; bem como encorajar o processo de dissolução de ligas; estimular a coalescência, flotação e remoção de inclusões não-metálicas. No entanto, a região de saída do fluxo gasoso (spout), Figura 1 é responsável por interações químicas indesejáveis entre o aço, escória e atmosfera, tais como: absorção de nitrogênio, hidrogênio; reoxidação e aprisionamento de partículas de escória, Figura 1b. Estes fenômenos são influenciados pela vazão, número e arranjo de orifícios de borbulhamento do gás; propriedades físicas da escória e do aço; bem como geometria da panela.

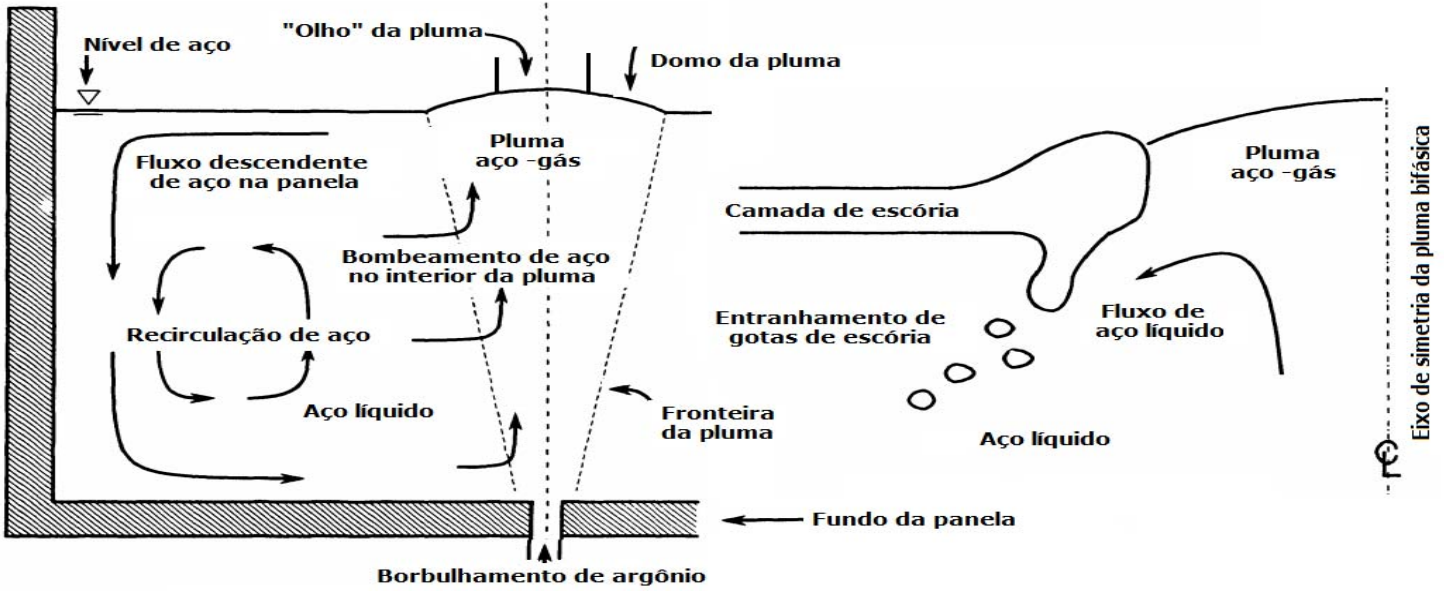

Figura 1. Aspectos fluidodinâmicos em panelas de refino do aço em presença de borbulhamento de gás inerte [1].

Shu \& Scheller [2] apontam que o aumento da vazão de argônio pelo fundo da panela de aço aumenta a abertura da pluma, contudo não influencia sobre o diâmetro da pluma no fundo da panela, Figura 2a. Por outro lado, o aumento da vazão de argônio incorre em aumento da velocidade do aço líquido e das bolhas na pluma bifásica, Figura 2, o que redunda em aumento das taxas de transferência de massa, calor e quantidade de movimento.
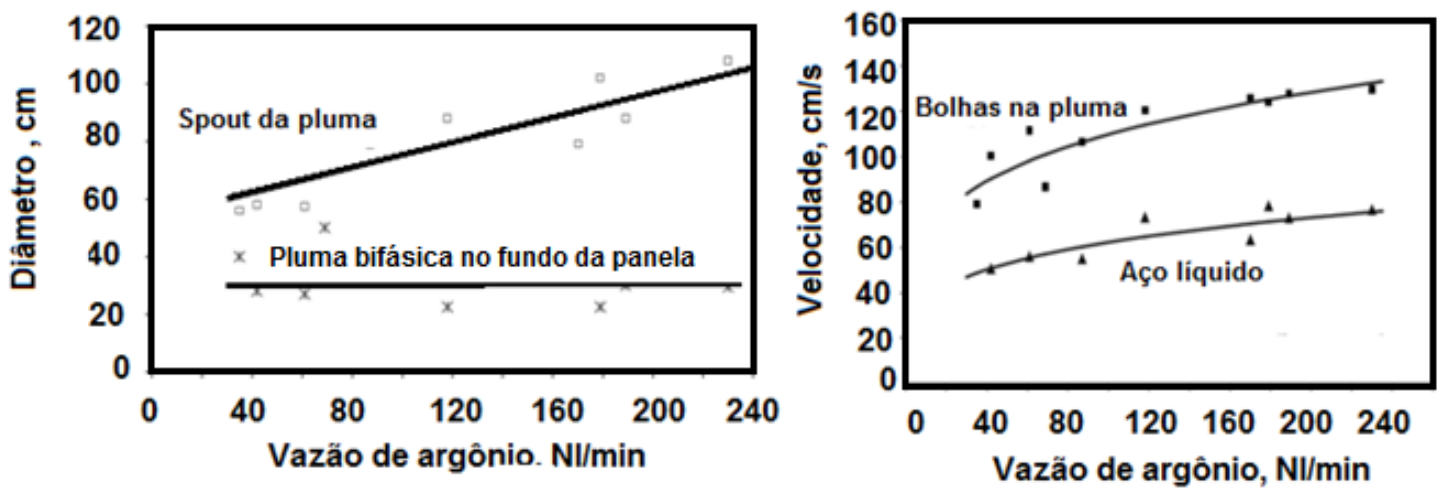

Figura 2. Influência da vazão de borbulhamento de argônio sobre o diâmetro do spout e da pluma e também sobre velocidade relativa das bolhas e velocidade do aço em panelas de refino de 30 toneladas [2].

* Contribuição técnica ao $45^{\circ}$ Seminário de Aciaria - Internacional, 25 a 28 de maio de 2014, 
Subagyo et al. [3], Mazumdar \& Evans [4] mostram que a vazão de borbulhamento do gás (Q); o nível de aço na panela (h); a espessura da camada de escória de cobertura $(\mathrm{H})$ e o diâmetro do orifício de borbulhamento influem sobre a área da abertura do olho da pluma $\left(\mathrm{A}_{\mathrm{es}}\right)$. Estes pesquisadores apontam que a abertura do olho da pluma pode ser caracterizada pelo adimensional de Froude $\left(Q^{2} / g H^{5}\right)$, Figura 3. Nota-se que o aumento do adimensional de Froude redunda em aumento da relação $A_{e s} /(h+H)^{2}$, isto é, elevação da área do olho da pluma, Figura 3a. De igual maneira, um dado valor do adimensional de Froude, o aumento da altura de escória faz decrescer a magnitude de $A_{e s} / h^{2}$, isto é, a área do olho da pluma, Figura 3.
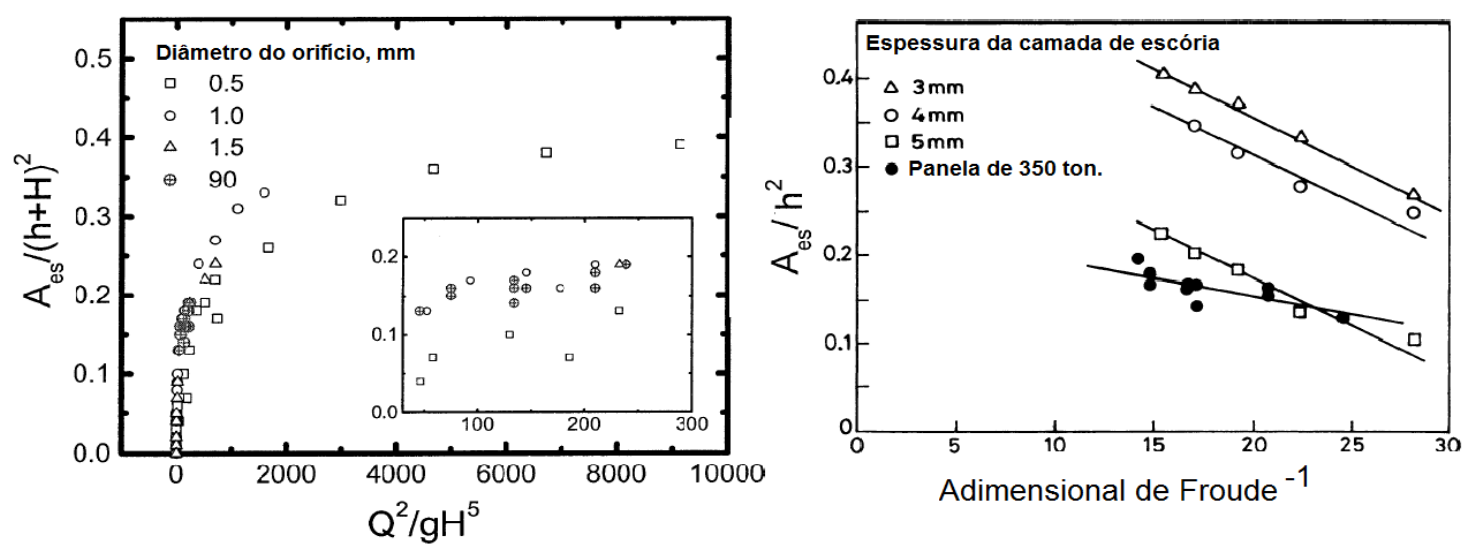

Figura 3. Efeitos do adimensional de Froude, diâmetro dos orifícios de borbulhamento e vazão de gás sobre as relações adimensionais $A_{\text {es }} /(h+H)^{2}$ e $A_{\text {es }} / h^{2}$ (a) Subagyo \& Brooks [3], (b) Mazumdar \& Evans [4].

O tempo de misturamento do banho na panela de refino do aço é função de diversos parâmetros operacionais, tais como: nível, composição e temperatura do banho; espessura, composição, temperatura da escória; configuração do sistema de borbulhamento de gás pelo fundo da panela. ZHU et al. [5] reportam que o tempo de misturamento do aço, na panela de refino secundário, é influenciado pela configuração do sistema de borbulhamento de gás e pela energia de agitação do banho, tal que:

$$
\tau_{\text {mist }}=8,52 \varepsilon^{-0,33} N^{0,33} \quad \text { para } N=1-3
$$

onde $\varepsilon$ e $\mathrm{N}$ representam a densidade de energia de agitação (W/kg) e o número de pontos de borbulhamento do gás inerte no fundo da panela. A densidade de energia de agitação do banho, decorrente da injeção do gás pelo fundo da panela de refino, é expressa como:

$$
\varepsilon=6,18 \times 10^{-3} \frac{\mathrm{QT}}{\mathrm{M}_{\mathrm{L}}}\left[\ln \left(+1+\frac{\rho_{\mathrm{L}} \mathrm{g} \mathrm{H}}{10^{5} \mathrm{P}}\right)+\left(1-\frac{273}{\mathrm{~T}}\right)\right]
$$

onde $\mathrm{Q}=$ vazão do gás, $\mathrm{Nm}^{3} / \mathrm{min} ; \mathrm{T}=$ temperatura do aço, $\mathrm{K} ; \mathrm{M}_{\mathrm{L}}=$ massa do banho metálico, toneladas; $\rho_{\mathrm{L}}=$ massa específica do aço, $\mathrm{kg} / \mathrm{m}^{3} ; \mathrm{g}=$ aceleração da gravidade, $\mathrm{m} / \mathrm{s}^{2} ; \mathrm{H}=$ profundidade do sistema de borbulhamento do gás, $\mathrm{m} ; \mathrm{P}=$ pressão do gás no olho da pluma, bar.

* Contribuição técnica ao $45^{\circ}$ Seminário de Aciaria - Internacional, 25 a 28 de maio de 2014, 


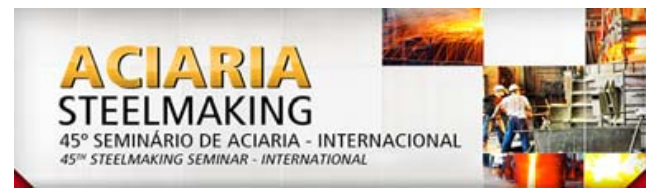

A Figura 4 mostra que o tempo decresce com o aumento da vazão do gás inerte e que este efeito é maior para o caso de configuração excêntrica $(-1 / 2 R$ e +1/2R) comparativamente com a configuração simétrica do sistema.

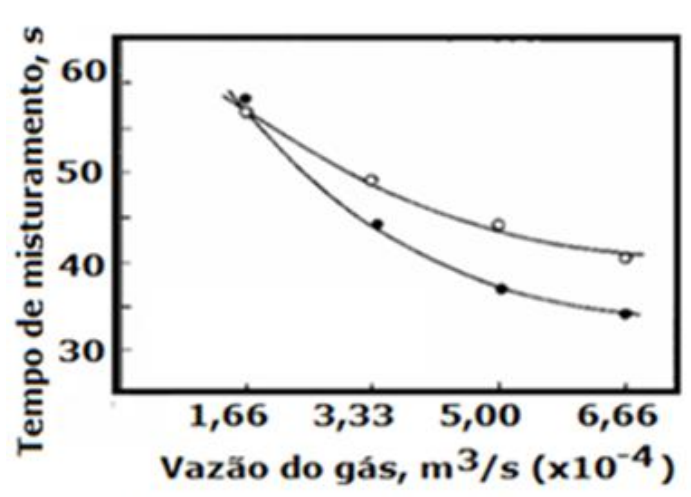

1 plugue, posição simétrica

2 plugues, posiçăo: $-1 / 2 R /+1 / 2 R$

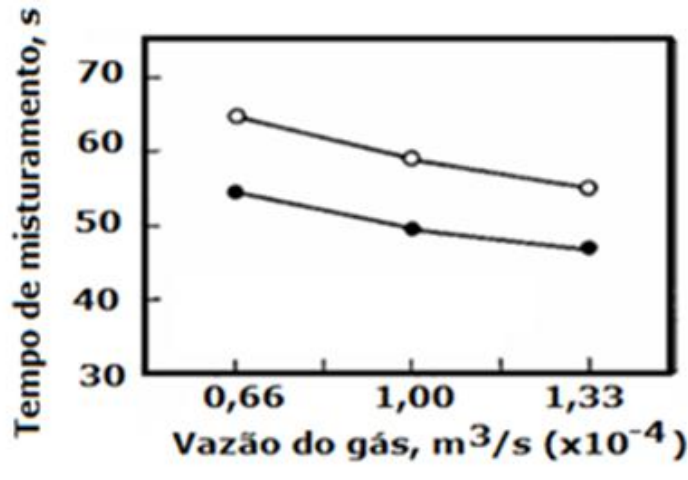

1 plugue, posiçăo assimétrica

2 plugues, posiçăo: $-1 / 2 R /+1 / 2 R$

Figura 4. Efeitos da vazão de borbulhamento de gás e da configuração de plugues porosos no fundo da panela sobre o tempo de misturamento [6].

Por outro lado, a escória de cobertura amortece a turbulência nas imediações abaixo da interface metal-escória, além de aumentar o tempo de misturamento no banho metálico, Figura 5. Sob condições de baixas vazões de borbulhamento do gás inerte, a camada de escória exibe um comportamento estagnado. Já para altas vazões do gás, além de retardar a turbulência na região subinterfacial metal-escória, a partir de uma vazão crítica encoraja-se a emulsificação escória-metal.
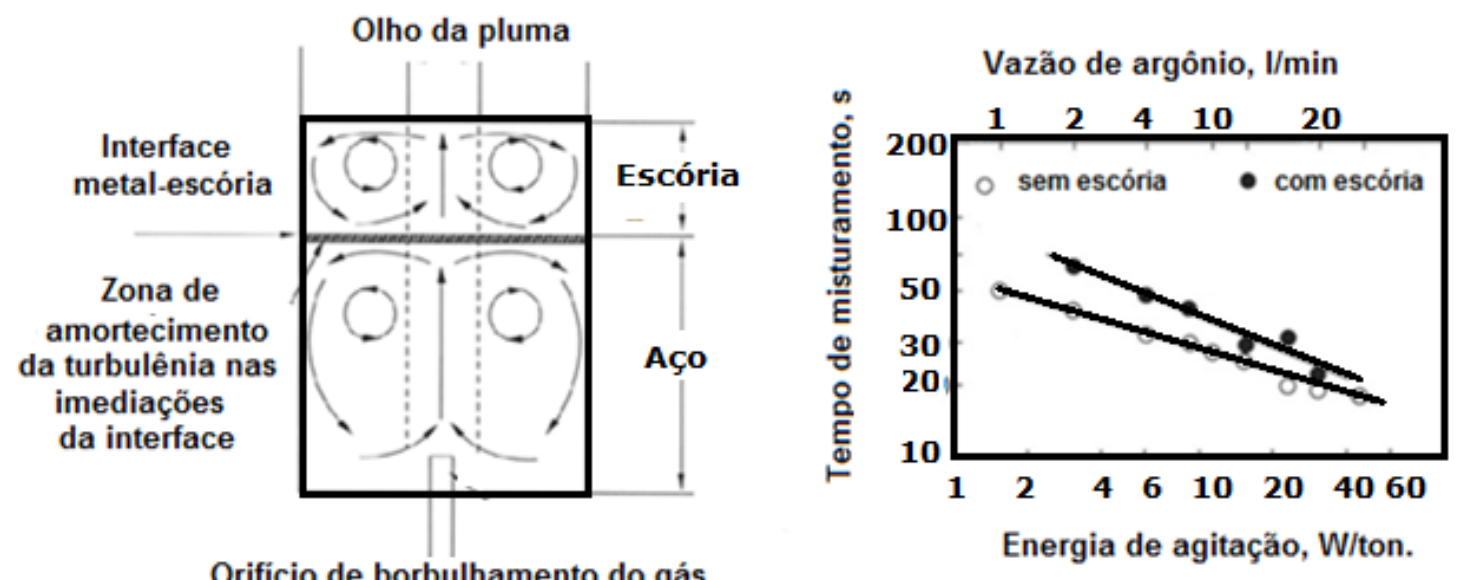

Figura 5. a) distribuição de fluxos na escória e no aço; b) olho da pluma e emulsificação metalescória [7].

\section{MATERIAIS E MÉTODOS}

O desempenho do sistema da agitação foi avaliado, num modelo de panela, através de medições de tempo de mistura na presença e ausência de camada de cobertura de escória e por meio de medições a área de abertura do olho da pluma. Para tanto foi construído um modelo físico em acrílico, em escala 1:5 $(\lambda=0,2)$, de uma panela de capacidade de 150 toneladas de aço, Figura 6. Dois arranjos assimétricos do sistema de borbulhamento de gás inerte foram instalados no fundo da panela, Figura 6. A vazão de borbulhamento de gás em cada plugue variou de 1 a 15lpm. 0

* Contribuição técnica ao $45^{\circ}$ Seminário de Aciaria - Internacional, 25 a 28 de maio de 2014, 
nível de líquido (aço) na panela foi fixado em dois valores: $46 \mathrm{~cm}$ (panela meio cheia) e $71 \mathrm{~cm}$ (panela a plena capacidade).

A abertura do olho da pluma foi avaliada medindo-se a área residual ocupada pela camada de óleo de silicone, tal como visualizada por meio de uma série frames obtidos por filmagem de topo da panela em operação. Os ensaios foram filmados com uma câmera convencional; posteriormente os dados foram tratados via software Virtual dub, de modo a transformar os vídeos em uma sequência de fotos. Para cada um dos ensaios foram selecionadas cinco fotos, que foram impressas e pesadas com o auxílio de uma balança de precisão. Posteriormente a região na qual ocorria a abertura do olho de pluma foi destacada e nova pesagem foi realizada. A relação entre o peso inicial e o final da folha de papel fornece uma estimativa do tamanho da abertura. Para a simulação da camada de escória, utilizou-se óleo de silicone com viscosidade de 100cst e 500cst e espessura de $1 \mathrm{~cm}, 3 \mathrm{~cm}$ e $5 \mathrm{~cm}$. De modo a avaliar o efeito da razão entre densidades de escória e aço utilizou água ou uma solução de $\mathrm{ZnCl}_{2}$ (de densidade igual a $1300 \mathrm{~kg} / \mathrm{m}^{3}$ ) para emular o aço.

A determinação de tempo de mistura consistiu na análise da dispersão de um traçador (solução de $\mathrm{KCl}$ ), adicionado sob a forma de pulso sobre a superfície do líquido na panela, Figura 6. Durante os experimentos, procedeu-se a medição contínua de vazões dos gases e de condutividade, via placa de aquisição de dados $A / D$, da variação da condutividade com o tempo, sendo os resultados armazenados no computador.
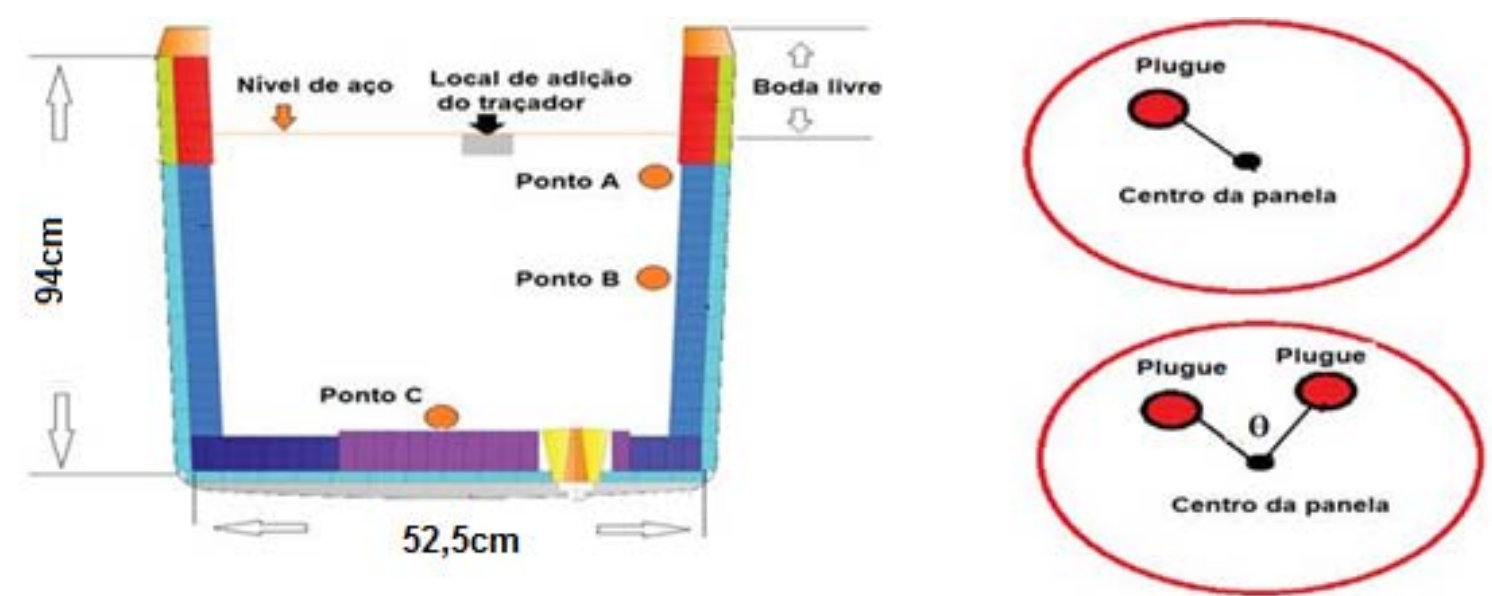

Figura 6. Identificação dos pontos de medição de condutividade na panela com um e dois plugues porosos.

Por meio da técnica PIV (Particle Image Velocimetry), Figura 7, foi possível mapear a distribuição de velocidades em uma dada região da panela. O equipamento PIV é dotado do sistema da DANTEC-2D e de sistema laser Dual Power- 65/15 400mJ, pulsos de $4 \mathrm{~ns}$, comprimento de onda entre $1064 \mathrm{~nm}$ entre $532 \mathrm{~nm}$, além de uma câmera CCD Flow-Sense 2ME para aquisição de imagens. A área de abrangência da câmera CCD é a de um quadrado de aproximadamente $10 \mathrm{~cm} \times 10 \mathrm{~cm}$, locada a $4 \mathrm{~cm}$ abaixo do nível do banho na panela. A análise de imagens for realizada via software Dynamics Studio - Dantec. Para todas as condições experimentais, foram adquiridas cerca de 280 imagens com intervalo de tempo entre as mesmas de $3000 \mu$ s e frequência de captura10Hz. Deve-se ressaltar que o mapa vetorial gerado, na área quadrada considerada, determina o perfil de velocidades em função da distância vertical a partir do topo da camada de aço líquido em direção ao seu interior.

* Contribuição técnica ao $45^{\circ}$ Seminário de Aciaria - Internacional, 25 a 28 de maio de 2014, 

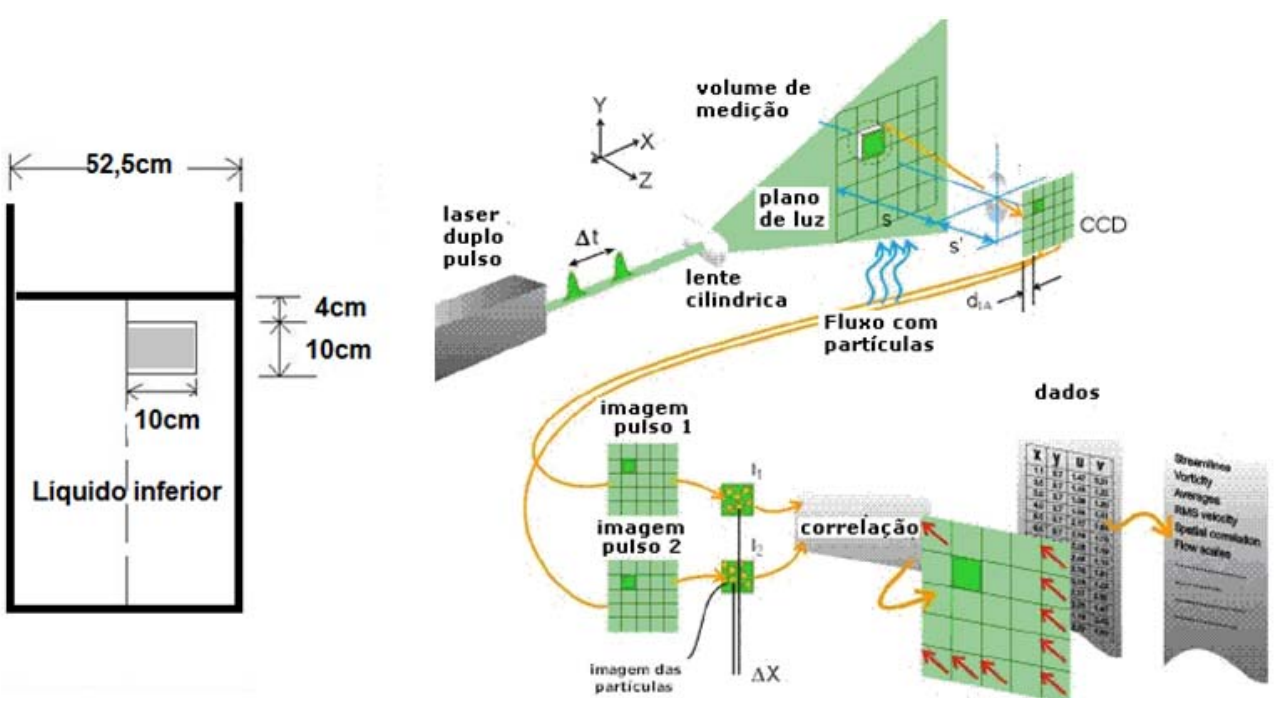

Figura 7. Modelo físico da panela de aço e detalhes da técnica PIV.

\section{RESULTADOS E DISCUSSÃO}

As Figuras 8 a 12 mostram que, independente do número de pontos de borbulhamento do gás instalados no fundo da panela, a abertura do olho da pluma aumenta com o aumento da vazão do gás, como esperado. No caso da panela dotada de um único plugue poroso, instalado na posição 2/3R, o olho da pluma tende a ser constante a partir da vazão do gás de 10lpm. Este comportamento, de estabilização da área de abertura do olho para vazões mais altas, se repetiu em todos os experimentos, refletindo o efeito das paredes da panela na contenção da camada de escória. Para uma dada vazão de gás e altura da camada de escória de cobertura, a abertura do olho da pluma tende a ser maior para o caso de dois plugues porosos comparativamente com um plugue poroso. A presença e aumento da espessura da escória fazem decrescer a abertura do olho da pluma. Este efeito mostra-se maior quando de escória de maior viscosidade. Os resultados indicam ainda que aumento da densidade e viscosidade do líquido emulador do aço na panela de refino secundário, mantendo as demais condições operacionais constantes, tende a fazer decrescer (de modo acentuado) a abertura do olho da pluma. Esta situação descreve melhor o sistema industrial, visto que, neste último, a razão entre a densidade da escória e do metal é da ordem de 3/7. A abertura do olho de pluma se mostra maior em panelas cheias (comparativamente a panelas parcialmente preenchidas) como seria esperado se o ângulo da pluma fosse mantido, mas o efeito não é linear, novamente pelo efeito das paredes.
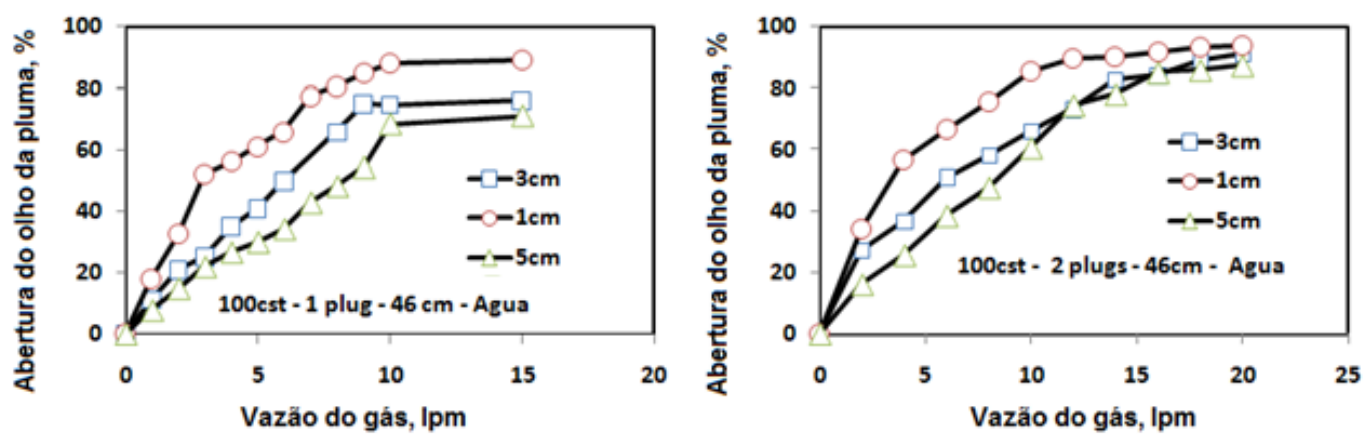

Figura 8. Efeitos da vazão de borbulhamento do gás, número de pontos de borbulhamento posicionados em $2 / 3 R$ e três espessuras da camada de escória sobre a abertura do olho da pluma: água-óleo; panela meio cheia.

* Contribuição técnica ao $45^{\circ}$ Seminário de Aciaria - Internacional, 25 a 28 de maio de 2014, Porto Alegre, RS, Brasil. 

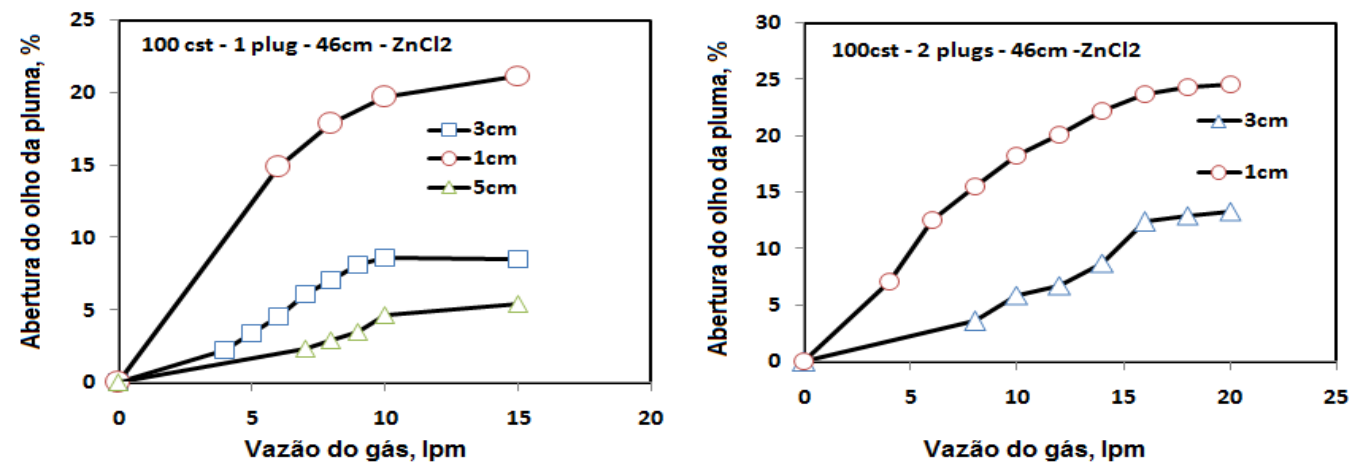

Figura 9. Efeitos da vazão de borbulhamento do gás, número de pontos de borbulhamento posicionados em $2 / 3 R$ e três espessuras da camada de escória sobre a abertura do olho da pluma: solução de cloreto- óleo; panela meio cheia.
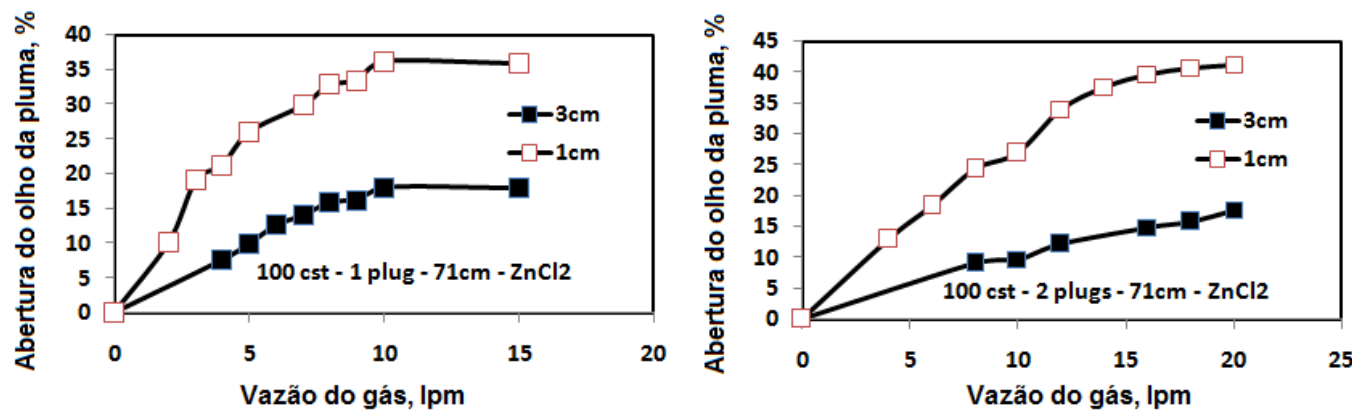

Figura 10. Efeitos da vazão de borbulhamento do gás, número de pontos de borbulhamento posicionados em 2/3R e duas espessuras da camada de escória sobre a abertura do olho da pluma: solução de cloreto-óleo; panela cheia.
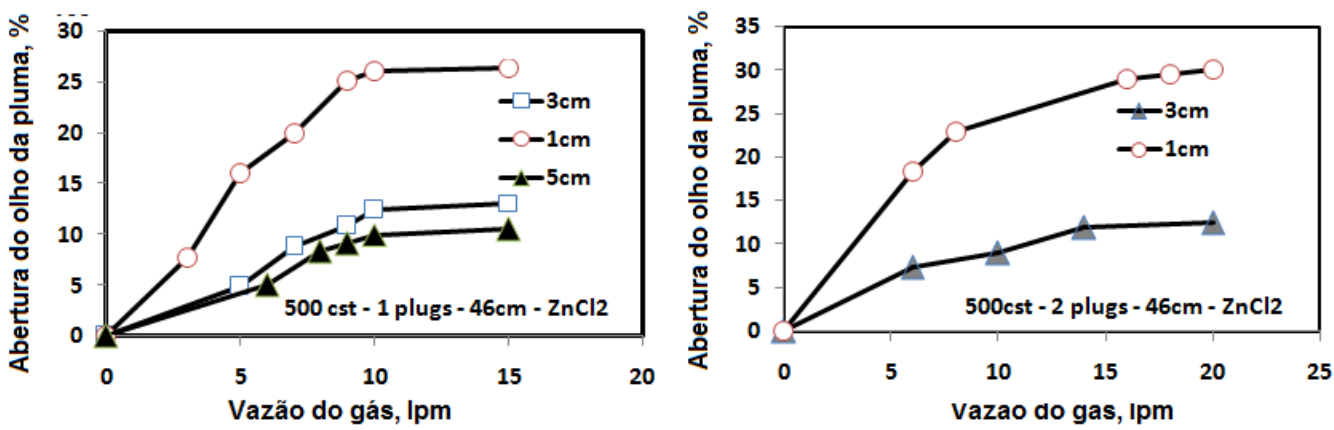

Figura 11. Efeitos da vazão de borbulhamento do gás, número de pontos de borbulhamento posicionados em 2/3R e três espessuras da camada de escória sobre a abertura do olho da pluma: solução de cloreto-óleo; panela meio cheia.
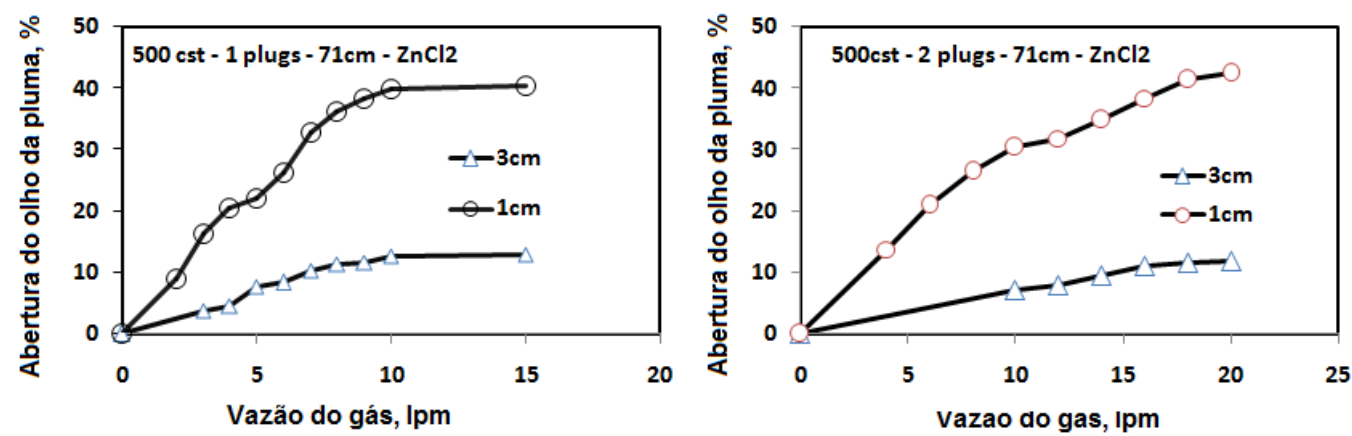

Figura 12. Efeitos da vazão de borbulhamento do gás, número de pontos de borbulhamento posicionados em $3 / 2 R$ e três espessuras da camada de escória sobre a abertura do olho da pluma: solução de cloreto - óleo; panela cheia.

* Contribuição técnica ao $45^{\circ}$ Seminário de Aciaria - Internacional, 25 a 28 de maio de 2014, Porto Alegre, RS, Brasil. 
Regressão múltipla empregando os resultados de cerca de 1445 experiências forneceu a correlação:

$$
\begin{array}{r}
\text { Abertura }(\%)=187-0,0039 \eta_{\text {óleo }}-0,281 \mathrm{H}_{\text {óleo }}+0,281 \mathrm{~h}_{\text {banho }}+2,239 \mathrm{Q}_{\text {gás }}+ \\
-5,52 \mathrm{~N}-143,73 \rho_{\text {banho }} \quad \text { com } \quad R^{2}=0,96
\end{array}
$$

onde $\eta_{\text {óleo }}=$ viscosidade do óleo de silicone $(100$ e $500 \mathrm{cSt}) ;\left(H_{\text {óleo }}=\right.$ altura da camada de óleo de silicone (1,3 e $5 \mathrm{~cm}) ; h_{\text {banho }}=$ nível do líquido inferior $(46$ e $71 \mathrm{~cm})$; $\mathrm{Q}_{\text {gás }}=$ vazão de borbulhamento do gás $(\mathrm{Ipm}) ; \mathrm{N}=$ número de plugues no fundo da panela $\left(1\right.$ e 2); $\quad \rho_{\text {banho }}=$ densidade do líquido inferior $\left(\mathrm{g} / \mathrm{cm}^{3}\right)$. Esta correlação matemática confirma que, para as condições operacionais investigadas, o aumento da vazão de borbulhamento do gás e altura de líquido na panela implicam em aumento da área de abertura do olho da pluma. E ainda que o aumento da espessura da camada de escória de cobertura, da viscosidade da escória, número de plugues porosos e massa específica do banho metálico. causam decremento da área do olho da pluma.

A Figura 13 mostra que, para um dado nível de líquido na panela e número definido de plugues porosos, o tempo de misturamento decresce com o aumento da vazão de borbulhamento do gás, como esperado. Nota-se ainda que diferentes regiões do líquido na panela exibem diferentes tempos de misturamento para uma dada vazão do gás, evidenciando, neste caso, uma ligeira falta de homogeneidade de fluxo e mistura. A região do topo da panela apresenta menor tempo de misturamento, o que pode ser atribuído à turbulência e as correntes de circulação causada pelo escape das bolhas gasosas da superfície do líquido. E ainda que o tempo de misturamento em panela dotada de dois plugues porosos tende a ser menor do que em panela equipada com um plugue poroso. Este fato é atribuído à minimização das zonas mortas no fundo da panela quando do borbulhamento de gás por meio de dois plugues porosos comparativamente com um plugue poroso. Para a altura de líquido de $71 \mathrm{~cm}$ os resultados exibiram o mesmo comportamento no que se refere aos tempos de misturamento nas várias regiões da panela de aço.
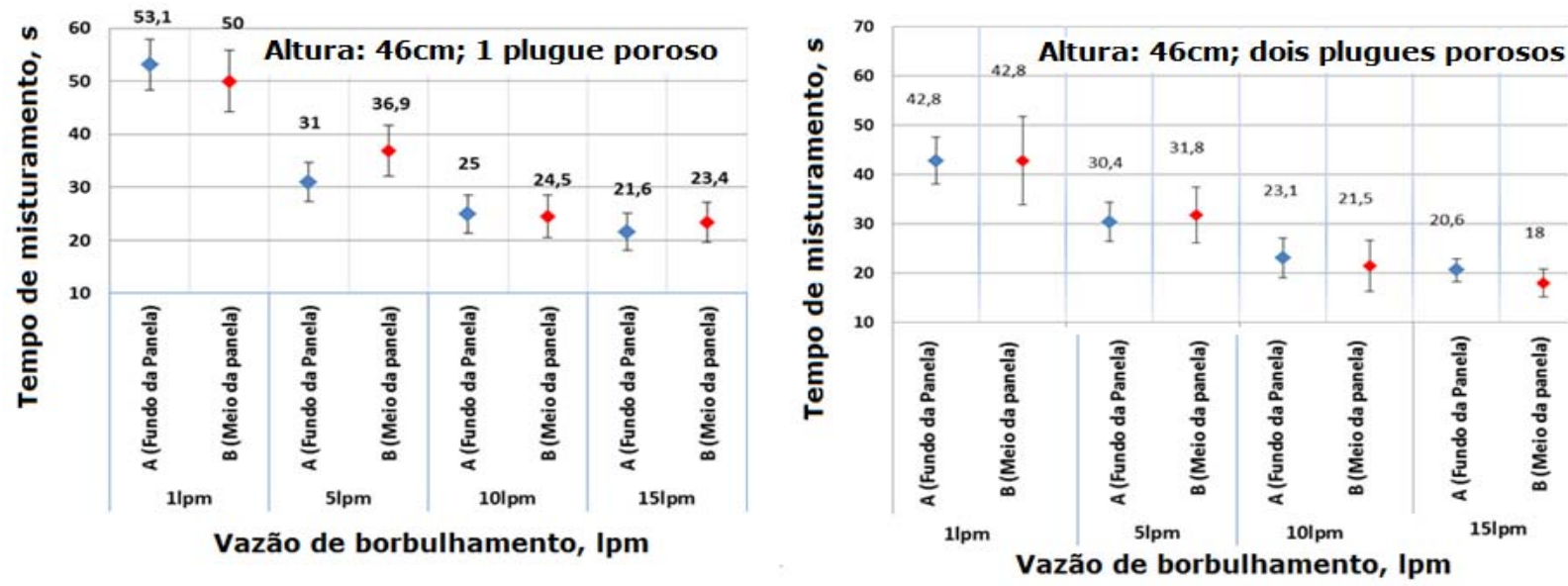

Figura 13. Efeito da vazão de borbulhamento sobre o tempo de misturamento na panela equipada com um e dois plugues porosos e altura de líquido de $46 \mathrm{~cm}$.

Neste trabalho o tempo de misturamento foi representado matematicamente pela equação:

$\tau_{\text {mist }}=a \varepsilon^{-b} \quad$ ou $\quad \ln \tau_{\text {mist }}=\ln a-b \ln \varepsilon$

* Contribuição técnica ao $45^{\circ}$ Seminário de Aciaria - Internacional, 25 a 28 de maio de 2014, 


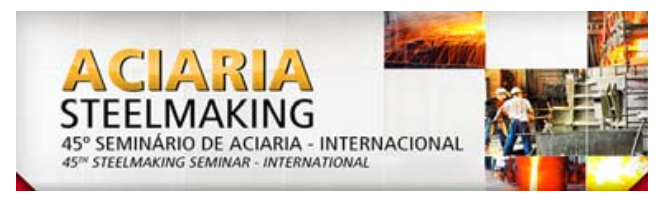

onde os coeficientes a e b foram estimados experimentalmente. As Figura 14 e 15 mostram a variação do tempo de misturamento com a energia de agitação induzida pelo fluxo gasoso em panelas de refino dotada com um e dois plugues porosos, em ausência e presença de escória de cobertura. Para uma dada vazão e arranjo do sistema de borbulhamento do gás, o tempo de misturamento mostrou-se aumentar na presença de escória de cobertura. Não é possível distinguir com nitidez um possível efeito do nível de líquido na panela: um nível mais elevado implica em maior interação entre a pluma bifásica e o banho, mas também em maior carga de líquido a misturar. Comparando as Figuras 14 e 15, nota-se que, para os dois níveis de banho na panela e para as configurações do sistema de borbulhamento de gás, o efeito da presença de escória sobre o tempo de misturamento mostrou-se virtualmente similar.
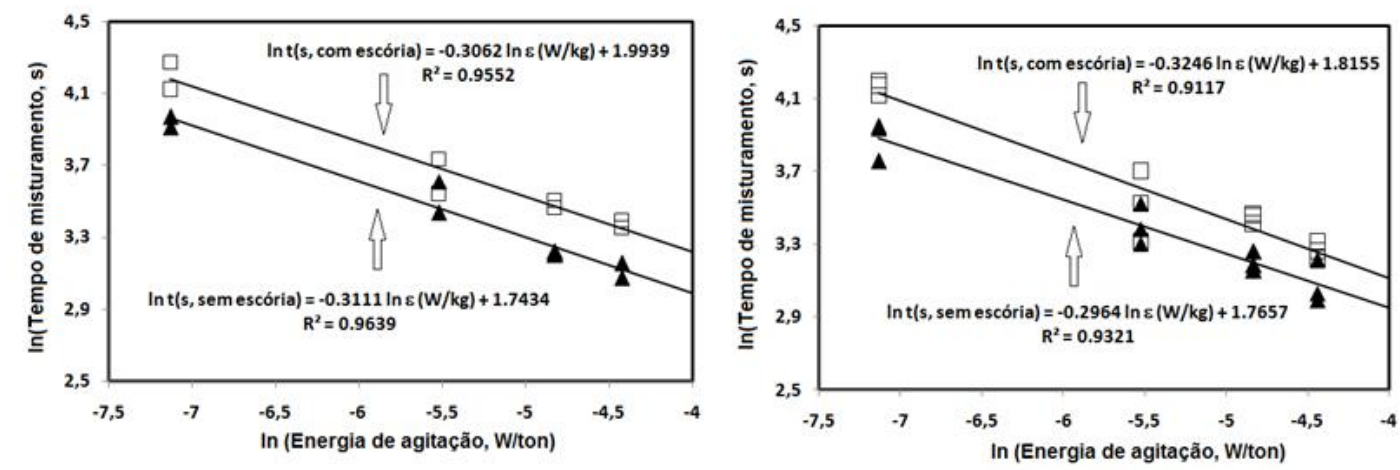

Figura 14. Efeito da presença de escória e da densidade de energia sobre o tempo de misturamento do aço na panela para um plugue poroso excêntrico no fundo da panela: a) nível de líquido $46 \mathrm{~cm}$; b) nível de líquido de $71 \mathrm{~cm}$.
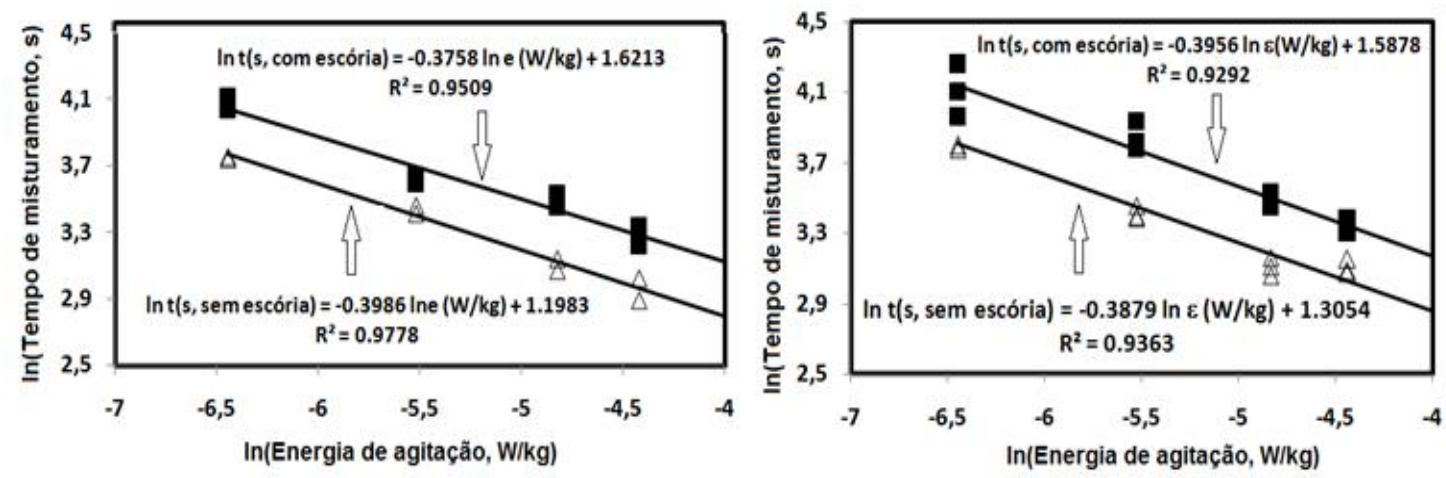

Figura 15. Efeito da presença de escória e da densidade de energia sobre o tempo de misturamento do aço na panela para dois plugues porosos excêntricos no fundo da panela: a) nível de líquido 46c; b) nível de líquido de $71 \mathrm{~cm}$.

As Figuras 16 e 17 mostram o mapa dos vetores velocidades em uma área de medição de $10 \mathrm{~cm} \times 10 \mathrm{~cm}$ via aplicação da técnica PIV. Nota-se que em ausência de escória (óleo de silicone), as velocidades nas regiões superficiais e subsuperficiais no topo do banho são maiores (vide em ordem decrescente as distribuições das zonas em vermelho $\rightarrow$ amarelo $\rightarrow$ verde, em ambas as Figuras) comparativamente com aquelas em presença de escória. A presença da fase emuladora da escória amortece o campo de velocidades na região interfacial e abaixo dela, modificando o perfil de velocidades, o qual é denotado pela mudança de coloração (vermelho $\rightarrow$ amarelo $\rightarrow$ verde). Na Figura 16, ao contrário da Figura 17, nota-se a ocorrência de altas velocidades (zona em vermelho), na região inferior e à direita da região

* Contribuição técnica ao $45^{\circ}$ Seminário de Aciaria - Internacional, 25 a 28 de maio de 2014, Porto Alegre, RS, Brasil. 
quadrada investigada. Por outro lado, na Figura 17, nota-se a diminuição da subregião de alta velocidade (zona em vermelho) e aumento da sub-região de velocidades decrescentes, contudo, ainda de altas (coloração amarelo $\rightarrow$ verde), na porção superior da área quadrada analisada. As distribuições das colorações em vermelho, amarelo e verde, na região subsuperficial quadrada mapeada, indicam a ocorrência de zonas de recirculação do banho na panela.

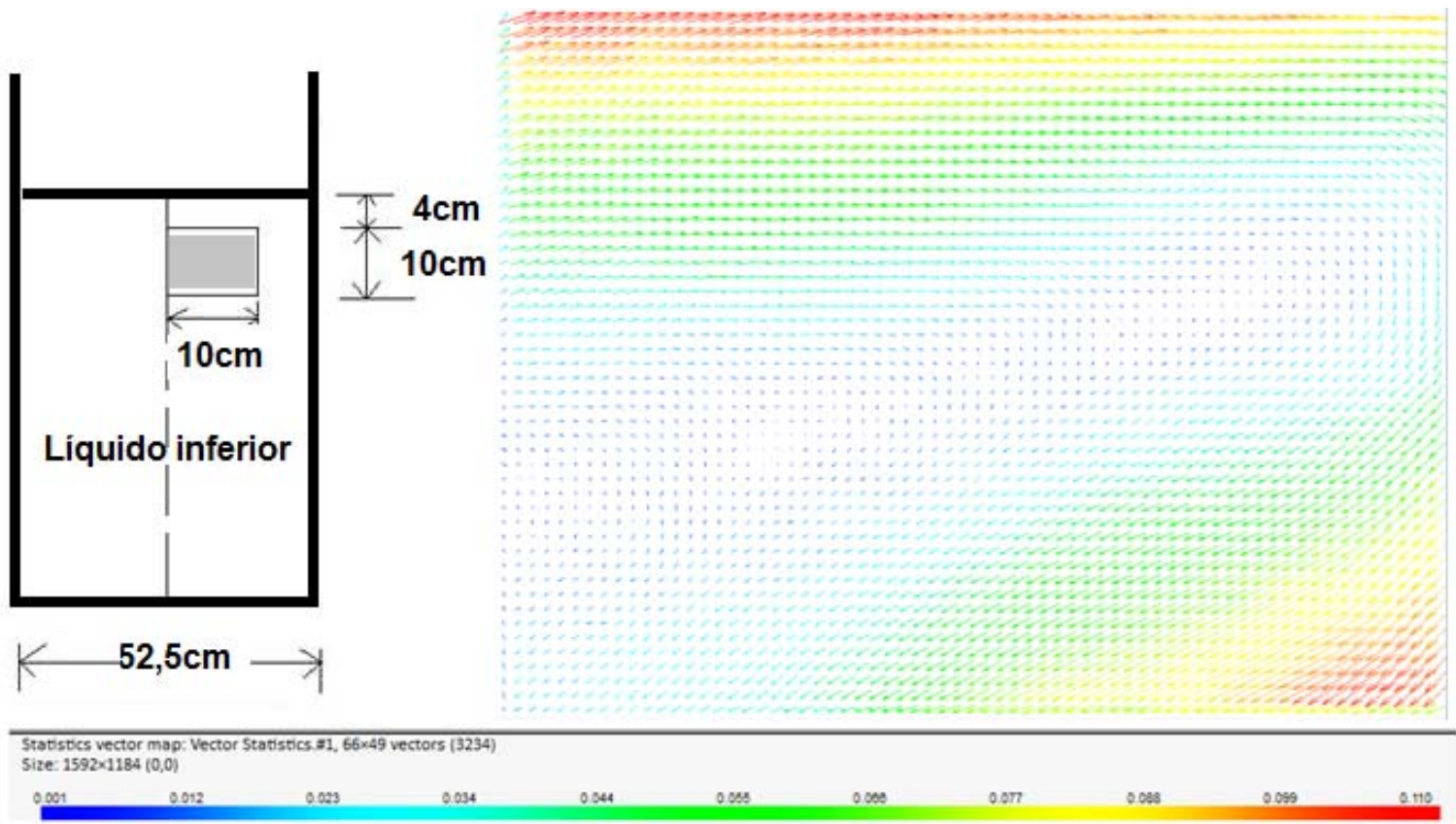

Figura 16. Campo de velocidades na região do molde: altura do banho $=46 \mathrm{~cm}$; vazão do gás = 15lpm, em ausência de escória.

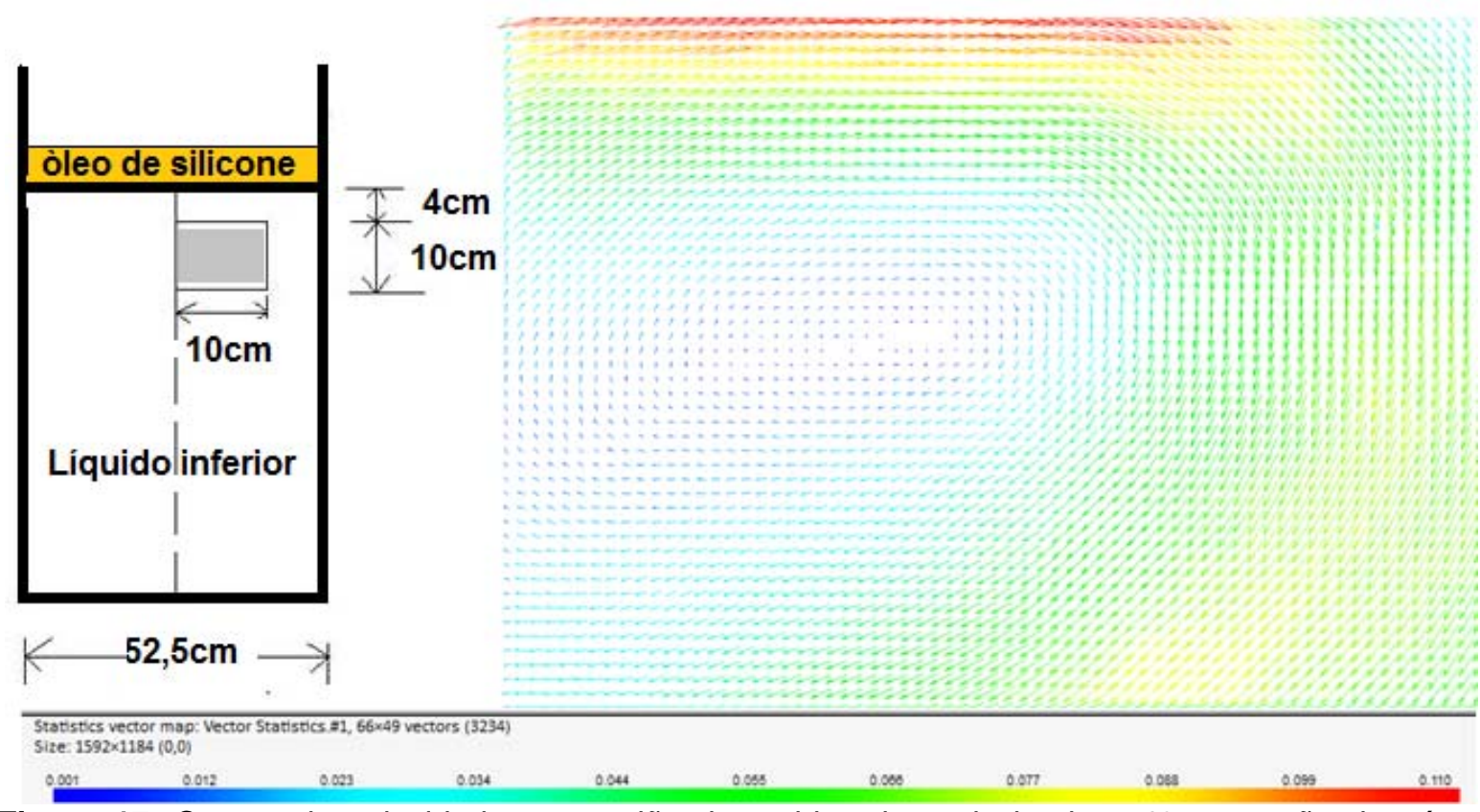

Figura 17. Campo de velocidades na região do molde: altura do banho $=46 \mathrm{~cm}$; vazão do gás $=$ 15lpm, em presença de escória.

Para as condições operacionais investigadas, a presença de escória de cobertura faz então crescer o tempo de misturamento do aço, o que pode ser explicado pela

* Contribuição técnica ao $45^{\circ}$ Seminário de Aciaria - Internacional, 25 a 28 de maio de 2014, Porto Alegre, RS, Brasil. 
mudança na estrutura de fluxo propiciada pelo atrito metal-escória. Este comportamento condiz com o reportado por Conejo et al. [8] e Patil et al.[9]. Estes últimos pesquisadores reportam ainda que a densidade e viscosidade da escória de cobertura exercem fracos efeitos sobre o tempo de misturamento. Contudo, a espessura da escória é fator mais influente sobre o tempo de misturamento do aço na panela, para uma dada condição operacional. Os resultados experimentais indicam ainda que, para as condições operacionais investigadas, a mudança de um plugue poroso excêntrico para dois plugues porosos excêntricos de mesmos diâmetros incorreu em decremento do tempo de misturamento. Este comportamento, por sua, vez, foi observado por Mandal et al.[6] e Su et al. [10], quando de altas vazões de borbulhamento do gás inerte. Contudo, Zhu et al.[5] salientam que um arranjo inadequado do sistema de borbulhamento pode ocasionar o aumento do tempo de misturamento do aço na panela.

\section{CONCLUSÕES}

Para as condições investigadas, o tamanho do olho da pluma e o tempo de misturamento são afetados pelo nível de líquido, espessura e viscosidade da escória de topo, densidade do metal, vazão do gás inerte e posição dos plugues porosos no fundo da panela. O tempo de misturamento do banho mostrou-se decrescer com o aumento da vazão do gás inerte, aumento do número de plugues porosos, contudo decresce com a presença e aumento da espessura da camada de escória. Já o tamanho do olho da pluma tendeu a decrescer com o aumento da espessura e viscosidade da escória de cobertura, contudo, a aumentar com a vazão do gás pelo fundo da panela. $O$ aumento do número de plugues porosos tende em provocar 0 coalescimento e aumento do tamanho da área do olho da pluma.

\section{Agradecimentos}

À FAPEMIG e à CAPES e ao CNPq pelo apoio financeiro.

\section{REFERÊNCIAS}

1 Shu Q, Volkova O, Lachmann S, Scheller PR. Modification of inclusion composition in steel during secondary metallurgical ladle treatment - A comprehensive process simulation model. In: AISTech 2011 - vol. II; 2011. p. 537-549.

2 Shu Q, Scheller PQ. Modification of inclusion composition in steel during secondary metallurgical ladle treatment. Freiberg University of Mining and Technology; 2011. p.144.

3 Subagyo, Brooks GA, Irons GA. Spout eyes area correlation in ladle metallurgy. ISIJ International. 2003;43(2): 262-263.

4 Mazumdar D, Evans JW. Some considerations concerning empirical correlations for plume (spout) eye area in slag covered metallic melts. ISIJ International. 2003;43(12): 2076-78.

5 Zhu M-Y, Inomoto T, Sawada K, Hsiao T-C. Fluid flow and mixing phenomena in the ladle stirred by argon through multi tuyere. ISIJ International. 1995;35(5):472-79.

6 Mandal J, Patil S, Madan M, Mazumdar D. Mixing time and correlation for ladles stirred with dual porous plugs. Metallurgical Transactions and Materials Transactions. 2005;36B:479-87.

7 Haida O, Emi T, Yamada S, Sudo F. Scaninject II - Part I. In: $2^{\text {nd }}$ International Conference on Injection Metallurgy Organized; 12-13 June 1980; Lulea Sweden. Lulea: MEFOS and Jerkontoret; 1980.

* Contribuição técnica ao 45 Seminário de Aciaria - Internacional, 25 a 28 de maio de 2014, 


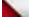

8 Conejo AN, Kitamura S, Maruoka N, Kim S-J. Effects of top layer, nozzle arrangement, and gas flow rate on mixing time in agitated ladles by bottom gas injection. Metallurgical and Materials Transactions B. 2013:44(4):914-923.

9 Patil SP, Satish D, Peranandhanathan M, Mazumdar D. Mixing models for slag covered, argon stirred ladles. ISIJ International. 2010;50(8):1117-24.

10 Su C-J, Chou J-M, Liu S-H, Chiang C-H. Effect of gas bottom blowing conditions on mixing of molten iron inside an ironmaking smelter. Materials Transactions. 2010;51(9):1594-1601.

* Contribuição técnica ao 450 Seminário de Aciaria - Internacional, 25 a 28 de maio de 2014, Porto Alegre, RS, Brasil. 